\title{
Research for educational change
}

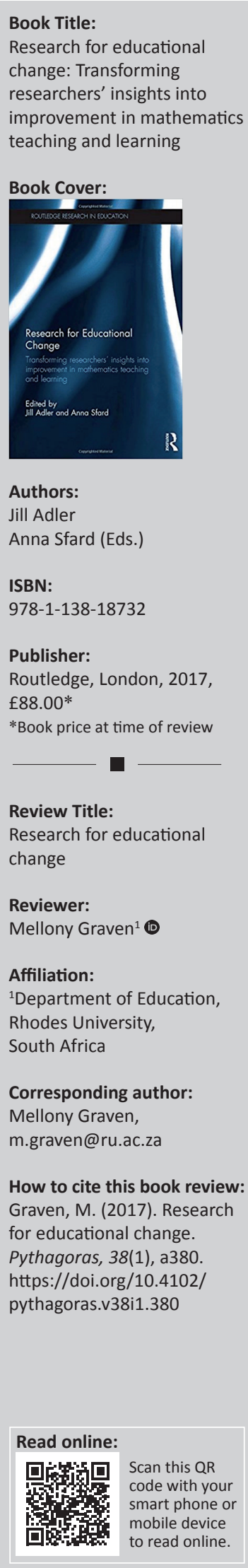

\section{Introductory comments}

It is not often I read an entire academic book almost in one sitting as was the case with this book. I found the insights captured compelling and thought provoking - pushing me to read on while constantly reflecting on the central question posed at the start of the introduction: 'How can educational research fulfil its commitment to educational practice?'

The book focuses on the difficult challenge of how to turn research into educational improvement, so that research-generated insights can impact mathematics teaching in classrooms particularly in contexts where teaching and learning are challenged by social injustice and poverty. To do this, the book adopts a quite novel structure well-suited to the aim. It creatively structures the chapters into two main parts, each focused on a different discourse - though these discourses engage with predominantly the same data set. The first discourse is that of researchers speaking to one another (Part 2) and the second discourse is that of researchers speaking directly to practitioners and teachers (Part 3). Part 1 and Part 4 provide introductory and reflective comment for these parts. Because of these two discourses the authors:

hope that the book, whether in its entirety or in specific parts, will be of use to a wide range of agents researchers, teachers, teacher-researchers, policy makers and curriculum developers. (p. 5)

While I agree that this book is relevant to these agents I found the book particularly useful for secondary teachers and teacher educators because it provides powerful illumination of how theory can and does inform practice in concrete ways - thus addressing the challenge of many pre-service and in-service teacher conceptions of theory being largely irrelevant to the day-to-day practice of teaching.

The book emerges from the work of the South African Wits Maths Connect Secondary (WMCS) Project, which Professor Jill Adler leads. In this project researchers (including national and international research collaborators such as Anna Sfard) and teachers collaborate to 'try to make a difference by proposing specific changes in specific practices' (p. 2). The project is argued to be special in two key ways:

First, the task of translating research into practice is actually performed here, not just discussed. Second, the project - being done in South Africa, a country whose education system is now widely recognized as failing the majority of learners - tackles the question of how to turn research into a lever for practice in the context of learning and teaching hindered by poverty, oppression and social injustice. (p. 2, italics in original)

While the WMCS Project provides the broad inspiration for the book the chapters focus on one lesson (recorded and transcribed) of one participating mathematics teacher referred to as $\mathrm{Mr} \mathrm{T}$. The lesson on quadratic equations and inequalities is with a Grade 11 class of students in a township fee-paying school in Gauteng (a highly urban province of South Africa). Mr T's school, as expanded on in Chapter 2, is considered a relatively typical school sharing multiple resource challenges with what Shalem and Hoadley (2009) term 'schools for the poor', in which the majority of South African secondary teachers teach. Mr T is part of the WMCS professional development project. It is in this learning context of participation in this project - that brings researchers and teachers together to search for sustainable ways forward to the challenges in secondary mathematics education in South Africa - that Mr T agrees to have his lesson recorded and analysed from a broad range of research perspectives. The researchers (who include the authors of the chapters herein) then analyse this data from various perspectives while maintaining a focus on the key aim of translating research into practice.

The introductory chapter by Jill Adler and Vassen Pillay provides a 'panoramic view' of the broader South African context while Chapter 2 sets the scene for the school, Mr T and the lesson data that forms the basis for the chapters in parts 2 and 3. Chapter 1 provides an excellent overview

Copyright: (c) 2017. The Authors. Licensee: AOSIS. This work is licensed under the Creative Commons Attribution License. 
of the current state of secondary mathematics education and mathematics education research in South Africa that makes excellent reading for those interested in understanding the many challenges teachers and learners face, in resource constrained contexts, as well as the opportunities such contexts open up for researchers. As the authors point out, this type of setting is still quite rare for mathematics education research, which tends to be conducted in more affluent environments. The book then offers 'another attempt at correcting this imbalance' (p. 6).

\section{Two discourses: Researchers to researchers; researchers to practitioners}

Part 2 and Part 3 are the heart of the book. In Part 2 researchers analyse $\mathrm{Mr}$ T's lesson data from a range of different perspectives using a discourse of researchers speaking to one another in a way that highlights insight into the teaching and learning process. So Anna Sfard analyses the lesson from her commognitive perspective, Jill Adler and Erlinda Ronda from their Mathematics Discourse in Instruction framework developed as a key part of the WMCS Project, Anthony Essien analyses the dialogic and argumentation structures in the lesson, while finally Kate le Roux bring a discourse analysis to bear on the lesson.

The Mathematics Discourse in Instruction perspective is particularly interesting in that it is a framework that emerges from the WMCS Project and is a framework that is used, alongside lesson study design, to engage with teachers on their practices. In this respect it provides a powerful boundary object (as elaborated by Hamsa Venkat in Chapter 12) for researchers and teachers, like $\mathrm{Mr} \mathrm{T}$ and $\mathrm{Ms} \mathrm{H}$. Ms $\mathrm{H}^{\prime} \mathrm{s}$ teaching data is brought into Part 3 by Adler and Ronda when translating 'research insights to teaching a lesson'. As Setati points out in her Afterword, Mathematics Discourse in Instruction 'enables Adler and Ronda to point to strengths and weaknesses in Mr T's lesson, avoid some deficit language, and also have productive conversations with teachers that inform action' (p. 211).

In Part 3 of the book the discourse shifts from speaking to fellow researchers to speaking directly to education practitioners and in particular to teachers. This is where 'the translation from research to practice takes place' (p. 5) and it is this part that I believe will be particularly of use for teacher educators. The chapters here seek to communicate, as clearly as possible and in a practitioner-oriented discourse, the implications of the insights gathered from careful lesson analysis (reported in Part 2) for impacting on practice. Each of the researchers thus here takes up the innovative task of bridging discourses and addressing different practitioners (teachers, curriculum designers, professional developers and even concerned newspaper readers). The innovation of this exercise and the change in discourse is most clearly visible in the innovative format of letters to Mr T provided in Chapters 7 and 9 by Anna Sfard and Audrey Msimanga (who collaborated with Anthony Essien on his analysis of dialogic and argumentation structures of Mr T's lesson in Chapter 5) respectively. This novel approach deserves some elaboration not only because it provides a powerful means of shifting researcher to researcher discourse to researcher to practitioner discourse, but also because it illuminates tensions in navigating the deficit trap, as referred to in Part 4, and which I elaborate on in the final section of this review.

In Anna Sfard's eloquently written letter to Mr T in Chapter 7 titled 'Teaching mathematics as an exploratory activity: A letter to the teacher' she shares with $\mathrm{Mr} \mathrm{T}$ insights gained from her analysis in Chapter 3 that drew on her discursive commoginitive perspective and in particular her notion of ritual and explorative participation (Sfard, 2008). In the letter she explains the difference between two modes of doing mathematics, namely the ritualised and explorative and argues for 'the superiority of explorative mathematics' (p. 133). This assumption of superiority, and the validity of the assumption, is dealt with in Chapter 3 where her analysis of $\mathrm{Mr} \mathrm{T}$ 's lesson reveals that 'the learners' mathematical discourse was ritualized rather than explorative' (p. 59). In her concluding remark in that chapter she reflects:

Whether I want it or not, this report on what I saw in Mr T's classroom will probably be perceived as judgmental and overly negative, whereas my right to judge is likely to be questioned on the basis of my not being sufficiently acquainted with the goals, ways of life, and backgrounds of the participants of the study, and above all, not cognizant of the past deprivations and the present needs of the wider community. (p. 60)

Sfard continues in Chapter 3 to argue in 'defence of the legitimacy and potential value' (p. 60) of her analysis, pointing to both her expertise in mathematics education and her longer-term involvement as a collaborator in the WMCS Project. In her letter to $\mathrm{Mr} \mathrm{T}$ she foregrounds her outsider status to the practice she is commenting on - beginning her letter with 'I am no longer a professional mathematics teacher myself' - then continues to outline the expertise she believes she brings. She argues that her many years of research experience have enabled her the privileged position of viewing and analysing lessons and transcripts multiple times, 'with all the time in the world to ask questions and test possible answers' (p. 123) and this enabled her to:

perfect my ways of constructing interpretations and then, after trial, improve my tools as an interpreter even further. All this made me aware of things that usually escape the attention of teachers, who are too busy with moment-to-moment decision making to notice. (p. 123)

Acknowledging that this is a 'luxury not many teachers can enjoy' (p. 123), she then continues to explain ways in which Mr T could change his practice to enable more explorative discourse and participation in his class. In her analysis she highlights that what learners are offered is what you get back from them. The letter communicates profound insights 
that maintain deep respect for the teacher and gratitude for the opportunity to engage with the lesson data. The final summarising remark is captured in the form of simple advice: attend to how you talk and make it clear that mathematics is not about symbols but rather about mathematical objects for which the symbols are but mere 'avatars' (p. 132).

This letter, and Msimanga's, provide powerful examples of how researchers might shift their discourse and style of writing, in order to speak more directly to teachers in ways that are respectful of their practice and acknowledge the inevitable differences between what teachers are able to notice and reflect on in the moment-to-moment and day-today practice of teaching and what researchers are able to notice when reviewing lesson data multiple times.

Furthermore, the letter aptly captures the tension in navigating respect for teacher practices while simultaneously pointing to 'deficiencies'. This tension is powerfully elaborated on by Einat Heyd-Metzuyanim in Chapter 11 who provides a critique of the way in which the book set out, as captured in the introduction, to avoid deficit interpretations that point to what is not present even while noting 'we do not wish to disown these critical descriptions' (p. 3). This is elaborated on in the next section as it relates to powerful meta-level learning offered by the book.

\section{Meta-level learning emerging from the chapters}

The three chapters in the final part, titled Beyond school: Some meta level learning, and Mamokgethi Phakeng's Afterword provide powerful reflections on what the book contributes. Einat Heyd-Metzuyanim, Hamsa Venkat and Nuria Planas each highlight what is made visible in the dialogue between discourses. Each brings a different but powerful perspective to what is offered by the book and each author compares and contrasts across the chapters and the discourses to 'pull the different threads together' (p. 5). These chapters and the Afterword jointly illuminate that while the book provides insights for how research might better impact teaching and how researcher and practitioner discourses might enter into productive dialogue, it does not provide easy ways to do this. Rather it reveals that in the process many tensions emerge.

In particular, the intention to avoid imposing deficit discourses on $\mathrm{Mr} \mathrm{T}^{\prime}$ 's practice is raised as a critical challenge as bringing a research perspective onto teaching inevitably focuses on what is present and absent in terms of what is relevant (placed in focus) for each perspective. Einat HeydMetzuyanim's chapter titled 'A meta level reflection on dialogue between discourses' powerfully captures this tension. Her chapter I believe makes key reading for all researchers navigating the ethical tension of deficit discourses present in their research writing. She points out that in each of the chapters in Part 2 deficits in the lesson are highlighted in relation to the actions of the teacher from the perspective taken -i.e. dominance of ritual over explorative, lack of exploratory talk, instruction that is authoritative rather than dialogic and texts provided to learners lacking opportunity for meaningful engagement with mathematical concepts. She asks:

how come most of what is said in these chapters refers to what cannot be seen in Mr T's classroom, what isn't there and not what is? Even when there is talk of what is, such talk is in relation to what isn't. (p. 176, italics in original)

Einat thus refers to "the trap of the "deficit talk" about mathematics instruction' (p. 176). She however engages further, urging us to consider ways to minimise this trap. This for me is one of the most exciting contributions of the book as this 'trap of deficit discourse' has weighed heavily on me since the start of my research with and on (after Setati, 2005) teachers in the mid-1990s. While I have worked against falling into this trap I have not had a frame for articulating and conceptualising how we might escape the trap. Einat argues that viewing school mathematics according to the 'Ring model' of the mathematics community is at the heart of the problem. That is, the model - with Mathematicians in the core ring embedded in a ring of Mathematics teacher educators embedded in the outer most ring of School mathematics teachers - necessarily leads to highlight the deficits of any of the outer rings over the innermost ring. Thus, by definition, school mathematics will often be ritual compared to the 'hard core' of the mathematical community (p. 177).

She continues to point out that if we were to see in school mathematics not what we wish to see, we would admit that 'school mathematics is first and foremost about grades and measures of achieving them (namely tests)' (p. 178) and so school mathematics is more about identities than about mathematical objects. Einat thus calls on researchers to rather seek to better understand the constraints, which are surprisingly similar across continents, and to view teachers as experts and central participants in their own communities. She instead argues for an overlapping model of professional communities rather than the ring model where the three communities of Mathematics teacher educators, Mathematicians and School mathematics teachers are each separate but with areas of overlap. In this respect building opportunities for rich dialogue and engagement between communities in these overlapping spaces is important to enabling movement beyond the deficit trap.

Indeed, even while struggling with such tensions the book makes a significant start towards illuminating possibilities for meaningful dialogue and engagement between communities. As Hamsa Venkat notes in Chapter 12, the mathematics teaching framework that Adler and Ronda present in Chapter 8, and which emerges from the WMCS Project, provides a useful boundary object 'commonly recognizable across the mathematics education research and mathematics teaching community, while providing spaces 
for development of activities within both of these communities in dialectical ways' (p. 190).

\section{Concluding remark}

I highly recommend this book for mathematics education researchers, teachers and teacher educators interested in increasing the impact of research on teaching and learning, particularly in contexts of social inequality and economic disadvantage, and to those with an ethical commitment to navigating emergent tensions such as the production of deficit narratives of teacher practices.

\section{References}

Shalem, Y., \& Hoadley, U. (2009). The dual economy of schooling and teacher morale in South Africa. International Studies in Sociology of Education, 19(2), 119-134. https://doi.org/10.1080/09620210903257224

Sfard, A. (2008). Thinking as communicating. New York, NY: Cambridge University Press. Setati, M. (2005). Researching teaching and learning in school from "with" or "on" teachers to "with" and "on" teachers: Conversations. Perspectives in Education, 23, 91-102. Available from http://hdl.handle.net/10520/EJC87300 